\title{
EXPERIMENTAL ANALYSIS OF A WASTE-HEAT-UTILIZATION-STRATEGY USING THERMOELECTRIC DEVICE IN C.I. ENGINE
}

\begin{tabular}{|l|l|l|}
\hline R. Srivastava & S.K. Dhiman & J.V. Tirkey \\
Department of Mechanical & Department of Mechanical & Department of Mechanical \\
Engineering, I.T.S. Engg College & Engineering, Birla Institute of & Engineering, Indian Institute of \\
Gr. Noida & Technology, Ranchi & Technology (BHU), Varanasi \\
\hline
\end{tabular}

\begin{abstract}
The present worldwide problem regarding automobiles is limitations of fuel and environmental pollution. When an internal combustion engine is operating, a large amount of energy is wasted as exhaust gas and with engine cooling. The efficiency of an internal combustion engine ranges from $30 \%$ to $40 \%$ and about $60 \%$ to $70 \%$ of the overall energy loss in a combustion engine is heat. The present experimental and computational study investigates waste heat recovery from the exhaust gas heat of an internal combustion engine using a thermocouple and heat pipes to produce electric power. This system proposes thermoelectric generation (TEG), working with heat pipes to produce electricity from a limited hot surface area. The current TEG system is directly connected to the exhaust pipe, to utilize the maximum possible heat available at the exhaust of C.I. engine. As designed, this heat recovery system produces a maximum of $1.54 \mathrm{mV}$ when the hot exhaust gas heats the evaporator surface of the heat pipe to $2770 \mathrm{C}$. The results obtained, promises great possibilities for application of this technology in future energy-efficient vehicles.
\end{abstract}

Keywords-Exhaust gas, thermoelectric generator, thermocouples, and heat pipes.

\section{INTRODUCTION}

$\mathrm{R}$ ecent trend about the best ways of utilizing the deployable sources of energy in to useful work is to reduce the rate of consumption of fuel as well as environmental pollution. Out of all the available sources, the internal combustion engines are the major consumers of fuel around the world. Out of the total heat supplied to the engine from the fuel, approximately, 30 to $40 \%$ is converted into useful mechanical work; the remaining heat is expelled to the environment through exhaust gases and engine cooling systems[1]. The recovery and utilization of wasteheat not only conserves fuel but also reduces the amount of waste heat and greenhouse gases damped to environment. In automobile engines significant amount of heat is released to the environment. For example, As much as $35 \%$ of the thermal energy generated from combustion in an automotive engine is lost to the environment through exhaust gas and other losses. The amount of such loss, recoverable at least partly or greatly depends on the engine load [2].However, in all the energy saving technologies used, engine exhaust heat recovery is considered to be one of the most effective. Many researchers recognized that Waste Heat Recovery from the engine exhaust gases has the potential to decrease fuel consumption without increasing emissions, and recent advancements in technology have made these systems viable and cost effective.

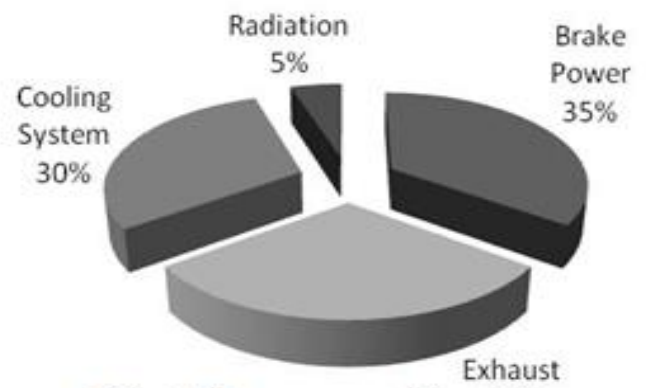

Heat to be recovered $\propto 30 \%$

Figure 1.1 Schematic shows total energy distributions of an I.C. engine.

In present investigation the recovery and utilization of waste heat is done using thermoelectric generators [3] which is based on the principle of Seebeck effect or thermoelectric effect. The principle of Thermoelectric is the creation of electric current from a temperature gradient or the creation of a temperature gradient from a current. Thermoelectric are based on the Seebeck Effect and the Peltier Effect, which were both discovered in the early 1800's. The Peltier Effect is widely known and used in many electric cooling applications that vary from small digital cameras to large refrigeration units and air conditioners. The Seebeck Effect runs in reverse of the Peltier Effect. Physicist Thomas Seebeck found that if you placed a temperature gradient across the junctions of two dissimilar conductors, electrical current would flow. This is the thermoelectric concept that would be of interest, because it takes the wasted heat and converts it to useful electricity. Thermoelectric power generators convert heat energy to electricity. When a temperature gradient is created across the thermoelectric device, a DC voltage develops across the terminals. When a load is properly connected, electrical current flows.

The present research posses a heat pipe thermoelectric generator [4] system which provides a large heated surface area, on which numerous thermocouples can be installed. As the heat pipe used is very efficient conducting device, it is possible to transfer a large amount of heat through the thermocouples to the heat sink. The performance of different thermocouples is described by: ZT $=(\alpha 2 \sigma / \lambda) \mathrm{T}$; where ' $\alpha$ ' is the Seebeck coefficient in $\mu \mathrm{VK}-1$; ' $\sigma$ ' is the electrical conductivity in $\mathrm{Sm}-1$; ' $\lambda$ ' is the thermal conductivity in $\mathrm{Wm}$ $1 \mathrm{~K}-1$ of thermoelectric material and ' $\mathrm{T}$ ' is absolute temperature in Kelvin. Coefficient of Performance (COP) of any thermocouple basically depends on the thermal 
conductivity and electrical conductivity of the material in use. For better COP, there is a need for materials with low thermal conductivity and higher electrical conductivity. In the present investigations, three easily available materials i.e., copper, iron and aluminum are selected to obtain the performance of three thermocouples TC1 (Al-Cu), TC2 (Cu-Fe) and TC3 (AlFe) [6]. The electrical and thermal conductivity of these materials in their purest form is in the order as: copper > aluminum $>$ iron under normal conditions. Out of these three thermocouples, TC3 was found to show good performance for various temperature differences. For future automotive vehicles, this technology offers increased fuel economy and improved engine efficiency by converting some waste heat to electricity.

\section{EXPERIMENTATION}

In order to vary the load on a C.I. engine to obtain various output parameters, the C.I. engine was coupled to a hydraulic dynamometer using a universal coupling. A movable assembly was fabricated to mount the hydraulic dynamometer and the C.I. engine, a movable assembly is fabricated so as to move the complete experimental set up to the easily available water sources, which is provided to the Hydraulic dynamometer for load variation on the engine. The schematic of movable assembly is shown in figure 2.1.

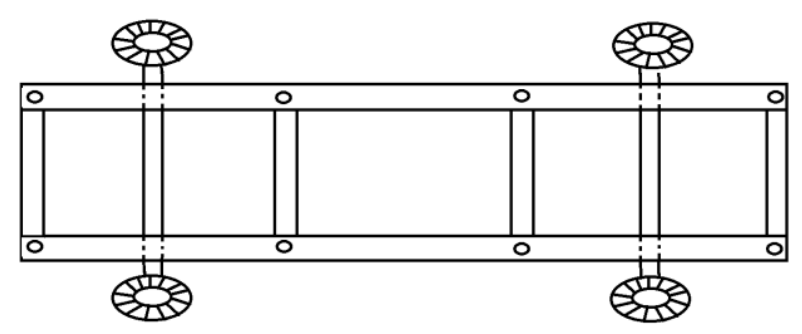

Figure 2.1: Schematic shows a movable assembly.

The shaft of both Hydraulic Dynamometer and the C.I. engine was made coincident using various spacers to avoid any kind of vibration and breakdown. The following objective is shown in figure 2.2.

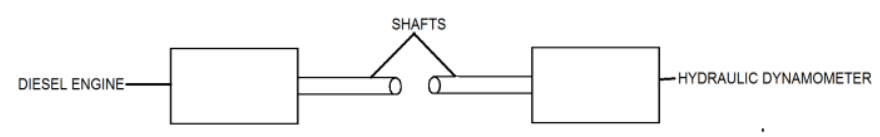

Figure2.2: Schematic shows shafts of hydraulic dynamometer and the diesel engine made coincident.

Both the Hydraulic dynamometer and the C.I. engine are coupled using the universal coupling as shown in figure 2.3.

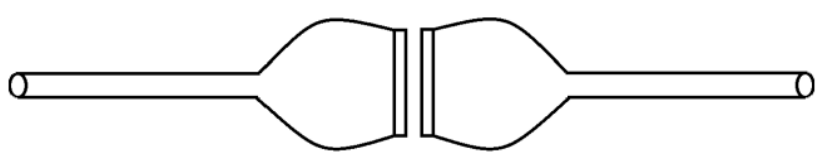

Figure 2.3: Schematic shows universal coupling.
A fuel measuring and supply system is fabricated which is attached to the inlet of the C.I. engine, start/stop valve were used to measure the accurate amount of fuel consumed by the engine for different load conditions. The mass of fuel consumed for varying load condition is measured using the fuel measuring cylinder as shown in Figure 2.4.

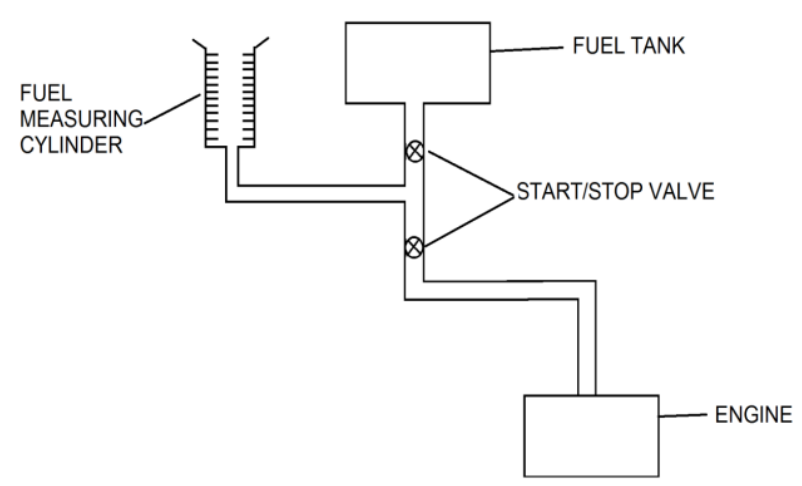

Figure 2.4: Schematic shows fuel metering device and supply system

The actual model fabricated is shown in Figure 2.5.

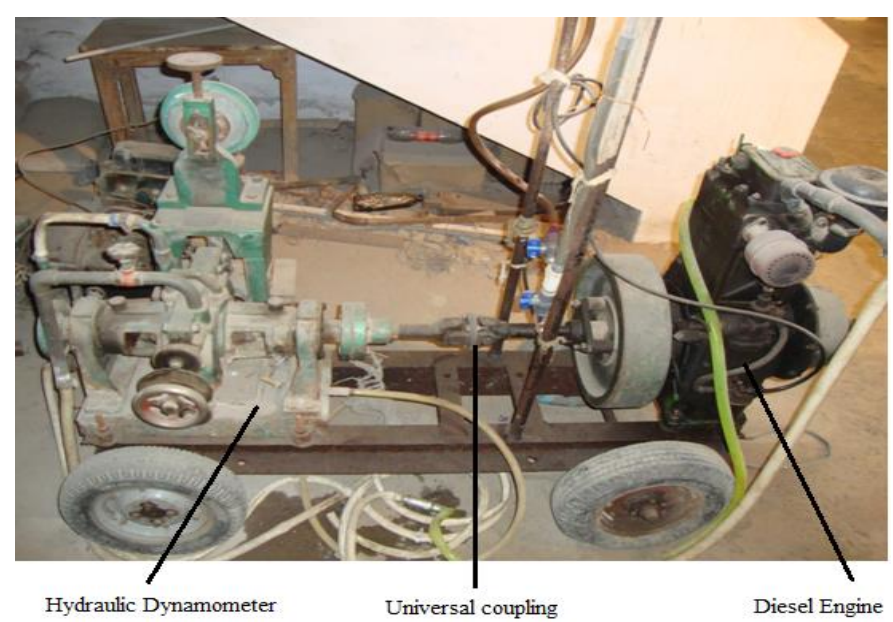

Figure 2.5: Schematic shows actual fabricated model.

When the load on an engine is increased more power is required to maintain the same speed of the vehicle, so more amount of fuel would be supplied from the injector nozzle to the engine cylinder during compression stroke, as a result of combustion the pressure and temperature inside the engine cylinder increases because of which the temperature of the exhaust gases coming out of the engine cylinder increases rapidly. The variation of mass of fuel consumed $\left(\mathrm{m}_{\mathrm{f}}\right)$ and the temperature $(\mathrm{T})$ of the exhaust gases released with Brake power is plotted on a graph for various load condition. The Brake power (B.P.) solely depends on the load provided by the hydraulic dynamometer, thus as the brake power increases mass of fuel consumption and the temperature of the exhaust gases also increases.Different temperature of the exhaust gases at different load was obtained using a thermometer. The temperature of cold junction was always maintained at room 
ELK

Asia Pacific Journals

temperature i.e. $27^{\circ} \mathrm{C}(300 \mathrm{~K})$.

The main components of the manufactured experimental TEG system, illustrated in Figure 2.5 are the main exhaust pipe, TEMs, and the heat pipe. The heat pipe used is a high conductive aluminium rod, $15 \mathrm{~cm}$ in length, $3.81 \mathrm{~cm}$ in outer diameter and $3 \mathrm{~mm}$ in thickness, it is incorporated between the exhaust of the engine and the muffler to utilize the maximum possible heat coming out of the engine [5]. This heat pipe act as the hot junction and ceramic material used act as the cold junction of the thermoelectric generator (TEG), two different wires (thermocouple) are winded on this heat pipe at one end and at other end they are attached to the cold junction. The heat pipe after winding thermocouples is made insulated at outer surface area using jute material. These thermocouples after the cold junction is attached to a scientific multimeter to complete the circuit and obtain the voltage generated due to the temperature difference at two junctions. Figure 2.6 shows theactual fabrication of the thermoelectric generator with heat pipe (aluminium rod) winded by aluminium and copper thermocouples.

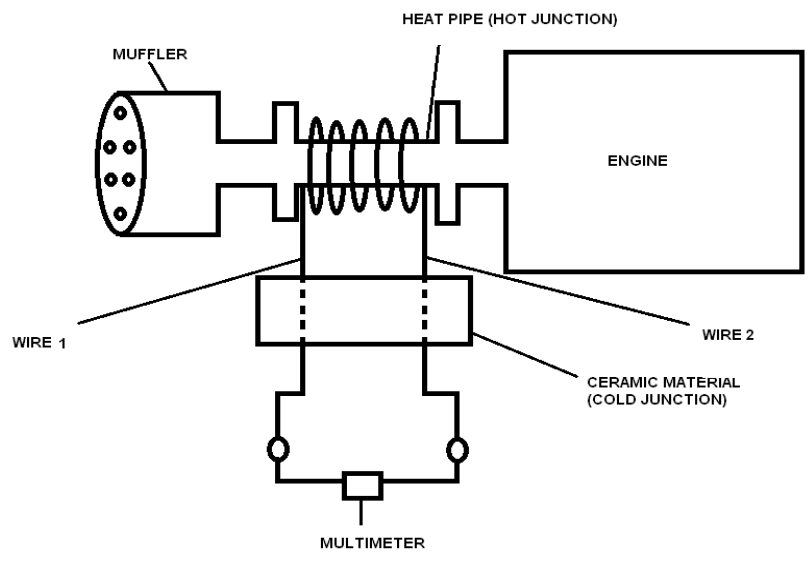

Figure 2.5: Schematic shows block diagram of TEG.

Different voltages for different type of thermocouples were obtained for varying temperature differences. The different thermocouples used are $\mathrm{Al}-\mathrm{Cu}, \mathrm{Fe}-\mathrm{Cu}$ and $\mathrm{Al}-\mathrm{Fe}$. Thermocouple TC1 and TC3 are just in twisted form because aluminum can't be welded under normal conditions and TC2 is fabricated (without the use of third material as a binder).

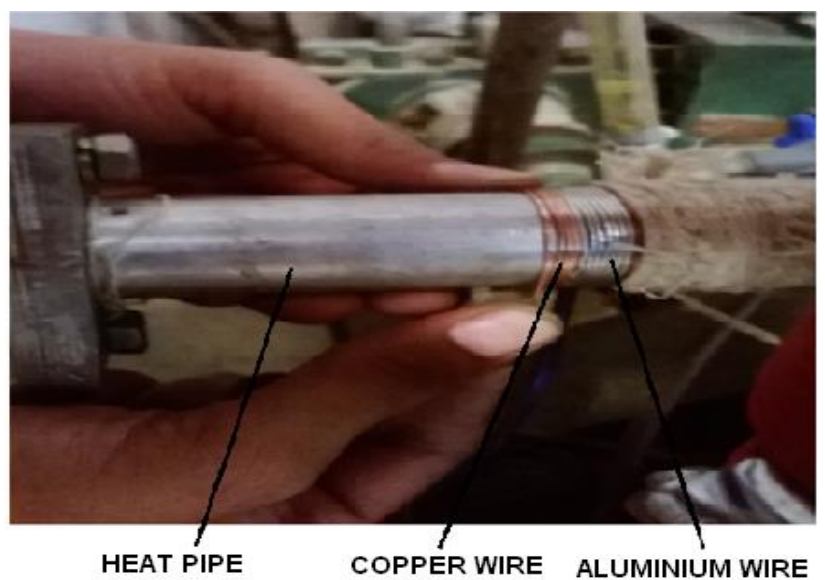

ELK Asia Pacific Journals - Special Issue ISBN: 978-81-930411-4-7

Figure 2.6: Schematic shows winding of thermocouples.

The specifications of all the three thermocouples are listed in table 2.1 [6].

TABLE 2.1

\begin{tabular}{llll}
\hline \hline THERMOCOUPLE & MATERIAL & $\begin{array}{l}\text { THERMAL } \\
\text { RESISTIVITY } \\
(\mathbf{o h m ~ m})\end{array}$ & $\begin{array}{l}\text { ELECTRICAL } \\
\text { CONDUTIVITY } \\
\left(\mathbf{S m}^{-1}\right)\end{array}$ \\
\hline $\mathrm{TC} 1$ & $\mathrm{Al}$ & $3.2 \times 10^{-7}$ & $3.13 \times 10^{6}$ \\
& $\mathrm{Cu}$ & $2.8 \times 10^{-7}$ & $3.6 \times 10^{6}$ \\
$\mathrm{TC} 2$ & $\mathrm{Fe}$ & $1.66 \times 10^{-6}$ & $6.024 \times 10^{5}$ \\
& $\mathrm{Cu}$ & $2.25 \times 10^{-6}$ & $4.4 \times 10^{5}$ \\
$\mathrm{TC} 3$ & $\mathrm{Al}$ & $3.2 \times 10^{-7}$ & $3.096 \times 10^{6}$ \\
& $\mathrm{Fe}$ & $1.5 \times 10^{-6}$ & $6.7 \times 10^{5}$
\end{tabular}

The voltage generated depends largely on the temperature difference across the thermocouple. When these thermocouples are studied for their voltage generation with the temperature ranging up to $250^{\circ} \mathrm{C}$, the curves obtained for voltage generation with temperature were parabolic in nature. Out of these three thermocouples, thermocouple (TC3) has

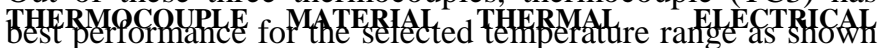
in fig 3.1 .

RESISTIVITY CONDUTIVITY

$$
\text { (ohm m) } \quad\left(\mathrm{Sm}^{-1}\right)
$$

\section{TC1 III. EXPERIMENTAL RES.UITIAAND DISGUSSIQN}

Graph 3.1 represents the experimental results obtained. As from the result we can see that as the brake power increases the mass of fuel consumption and the temperature of the exhaust gases increases. Thus by increasing load on an engine higher temperature can be obtained, temperature at the exhaust of the engine increases with increase in brake power. Different values of voltages are obtained at different temperature of the exhaust gases for different thermocouples.

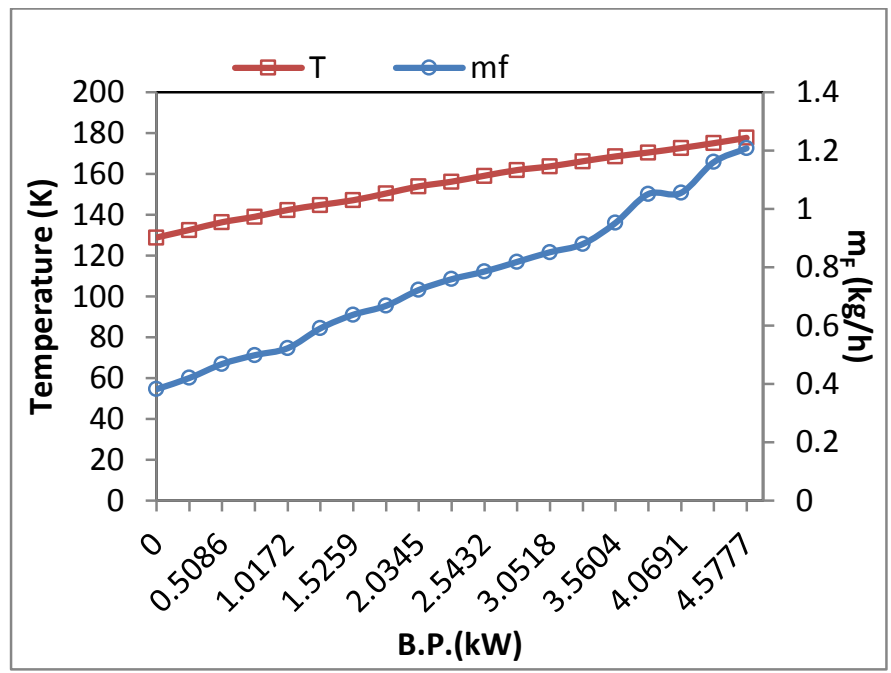

Graph 3.1: Variation of mass of fuel and temperature of exhaust gas with brake power.

Graph3.2 shows that in normal mode, voltage generated with 
temperature is maximumfor aluminium-iron thermocouple (TC3) for all temperature ranges with its maximum value of $1.542 \mathrm{mV}$ at a temperature difference of $250^{\circ} \mathrm{C}$. The experimental results from graph 3.2 conclude that thevoltage generated increases with increase in temperature of the exhaust gases, so higher voltages can be obtained for higher temperature. Aluminum-iron thermocouple shows better performance as compared to other combinations (i.e. copperaluminium TC1 \& copper iron TC2) indicating the importance of combination of materials with high electrical conductivity and low thermal conductivity. For TC3 combination, aluminum fulfills the requirement of high electrical conductivity where as iron has low thermal conductivity. Aluminum shows better prospects as one of the thermocouple materials, however, difficulty arises with aluminum for the fabrication of its thermocouple as aluminum does not fuse with other materials under simple laboratory conditions.

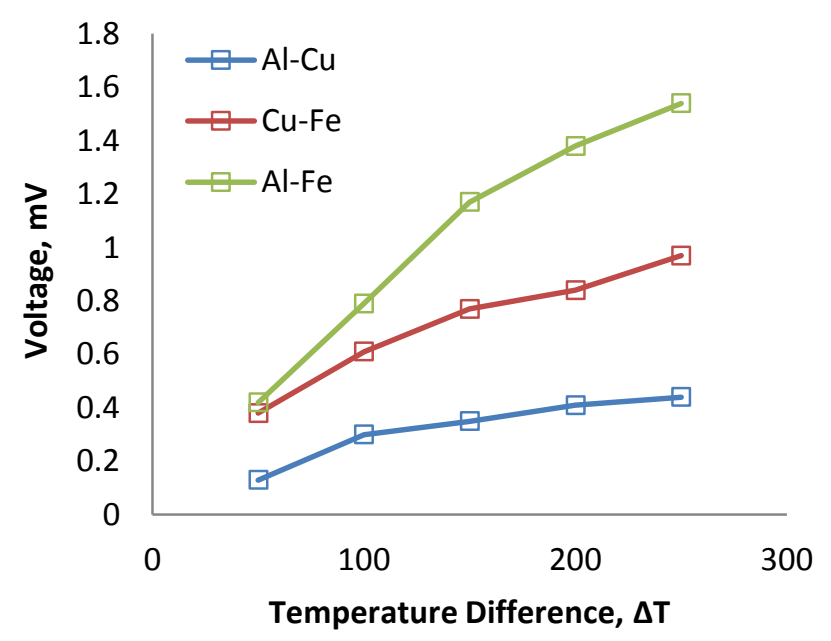

Graph 3.2: Variation of voltage with Temperature difference.

\section{Conclusion}

From the present investigations it is concluded that the voltage generated depends on the temperature of the exhaust gases, as the temperature of the exhaust gases increases the voltage generated also increases. Thus for a better performance of thermoelectric generator higher temperature at exhaust is required, so the heat pipe would be more effective when it is incorporated between the exhaust pipe and the muffler. When the heat pipe is incorporated between the muffler and the exhaust pipe maximum amount of heat can be utilized by the thermoelectric generator. The above results for voltage generation using thermoelectric generator concludes that the performance of $\mathrm{Al}-\mathrm{Fe}$ thermocouple is better than the other thermocouples used for normal mode of operation in lower as well as higher temperature range. All the three thermocouples were able to produce voltagesbut their magnitude is very low. Thus instead of using a single thermocouple for voltage generation, numerous thermocouples can be used to obtain a considerable amount of voltage. The semiconductor materials shows better electrical properties than the metal thermocouples, so semiconductors as thermocouples can be used to obtain higher voltages. A large number of N-type and P-type semiconductors can also be doped together to obtain effective voltage that will increase and enhance the performance and efficiency of the engine.

\section{REFERENCES}

[1] T. Endu, S. Kawajiri, Y. Kojima, K. Takahashi, T. Baba, S. Ibaraki, T. Takahashi, "Study on maximiszngexergy in Automotive Engines," SAE Int. Publication 2007-01-0257, 2007.

[2] M. Hatazawa, "Performance of a thermo acoustic sound wave generator driven with waste heat of automobile gasoline engine," transaction of the Japan society of Mechanical engineers 70 (689) (2004) 292-299. Part B.

[3] J. S. Jadhao, D. G. Thombare"Review on Exhaust Gas Heat Recovery for I.C. Engine”, International Journal of Engineering and Innovative Technology (IJEIT) Volume 2, Issue 12, June 2013.

[4] Francisco P. Brito, Jorge Martins, L.M. Goncalves and Rui Sousa Universidade do Minho "Temperature Controlled Exhaust Heat Thermoelectric Generation" 2012 SAE International,10.4271/2012-01-1214.

[5] X. Liu, Y.D. Deng, S. Chen, W.S. Wang, Y. Xu, C.Q. Su "A case study on compatibility of automotive exhaust thermoelectric generation system, catalytic converter and muffler" Elsvier International Journals 2(2014)62-66.

[6] Vinod Kumar, Jaspal Singh and S.S. Verma "Performance Comparison of Some Common Thermocouples for Waste Heat Utilization” Asian Journal of Chemistry Vol. 21, No. 10 (2009), S062-065.

\section{CONTACT INFORMATION}

F. A. Author, PG Student, Department of Mechanical Engineering at Birla Institute of Technology, Ranchi, Jharkhand, India (srv.rohan@gmail.com).

S. B. Author, Assistant Professor, Department of Mechanical Engineering at Birla Institute of Technology, Ranchi, Jharkhand, India (skdhiman@bitmesra.ac.in) T. C. Author, Assistant Professor, Department of Mechanical Engineering at Indian Institute of Technology (BHU), Varanasi, Uttar Pradesh, India (jvtirkey@gmail.com) 